\title{
Utilization of antenatal care services and factors affecting antenatal care visits in Pokhara sub-metropolitan city
}

\author{
Sabita Paudel ${ }^{1}$, Tarun Paudel ${ }^{2}$, Seshananda Sanjel ${ }^{3}$ \\ ${ }^{1}$ Medical officer, Ex-Serviceman Contributory Health Scheme Clinic, Indian Embassy, Kathmandu \\ ${ }^{2}$ Professor in General Practice and Emergency medicine; ${ }^{3}$ Associate Professor in community \\ Medicine \& Public Health, Karnali Academy of Health Sciences, Jumla, Nepal
}

Corresponding Author: Dr. TarunPaudel; Email: drtarunpaudel@gmail.com

\section{ABSTRACT}

Background: In context of Nepal, although the pregnant women from city areas contribute to maternal mortality, evidences of study of utilization of antenatal care services and factors affecting antenatal care visits (ANC) are focused in rural areas where health institutions are not easily available. The objective of this study was to identify ANC services utilization by eligible women in Pokhara sub-metropolitan city.

Methods: This was a cross-sectional study conducted applying face to face interviews with 240 eligible women bearing at least one youngest child below the age of two years. Structured and semi-structured questionnaire were used after translating into Nepali language and pretesting it in the field. Data entered in Microsoft excel were transferred in SPSS (Statistical package for social sciences) version 21 and analysis was carried out. Both descriptive and inferential statistics were computed. The significance was set at 0.05 level.

Results: Approximately $97.0 \%$ of women had visited ANC during their recent pregnancy and about $56.0 \%$ of women had $\geq 4$ ANC visits. Majority $(80.3 \%)$ of the women used to seek ANC checkup during their first trimester and nearly half (49.0\%) of the respondents belonged to younger age of 15-19 years. Women' (99.0\%) and her husbands' (86.0\%) educational level significantly impacted ANC visits. Women having fewer numbers of children (98.0\%) and nuclear family (99.0\%) had significantly higher ANC visits.

Husbands'and mother-in-laws'encouragement to go for ANC visits was significantly higher.All of the above mentioned parameters were statistically significant at $\mathrm{p}<0.05$ level.

Conclusions: There was variation in ANC service taking as per the encouragement from husband and motherin-law of the woman. Hence, awareness programs targeting husband and mother-in-law regarding importance ofANC services is suggested. Conduction of detailed study in futureto explore quality of services is recommended.

Keywords: Antenatal care visit (ANC), Service Utilization, Factor affecting ANC visit, Pokhara submetropolitan city

\begin{tabular}{|l|l|l|}
\hline \multicolumn{2}{|c|}{ Access this article Online } & Article Info. \\
\hline Quick Response Code & Website: & How to cite this article in Vancouver Style? \\
\hline & $\begin{array}{l}\text { Www.jkahs.org.np } \\
\text { antenatal care services and factors affecting } \\
\text { antenatal care visits in Pokhara sub-metropolitan } \\
\text { city. Karnali Academy of Health Sciences } \\
\text { 2020;3(1):1-11. }\end{array}$ \\
& $\begin{array}{l}\text { Received: March 5, 2020 } \\
\text { Accepted: April 10, 2020 } \\
\text { Published Online: April 12, } 2020 \\
\text { hol: } \\
\text { https://doi.org/10.3126/jkahs.v3i1.28658 } \\
\text { The DoI will be functional after the } \\
\text { issue is fully published online as well as } \\
\text { in printed version }\end{array}$ & $\begin{array}{l}\text { Conflict of Interest: None } \\
\text { Source of Support: None }\end{array}$ \\
\hline
\end{tabular}




\section{INTRODUCTION}

Antenatal care (ANC) is care of women during pregnancy. The primary aim of the antenatal care is to achieve at the end of a pregnancy a healthy mother and ahealthy baby. Ideally, this care should begin soon after conception and continue throughout the pregnancy. ${ }^{1}$ World health organization (WHO) defines antenatal care as a dichotomous variable, having had one or more visits to trained person during the pregnancy. It includes routine follow up provided to all pregnant women at primary care level from screening to intensive life support during pregnancy and up to delivery. ${ }^{2-4}$ Furthermore, WHO now recommends four focused ANC visit schedule for low risk pregnancies. ${ }^{3}$ Globally, the maternal mortality rate (MMR) fell by nearly $44.0 \%$ over the past 25years, to an estimated 216 maternal deaths per 100,000 live births in 2015, from an MMR of 385 in 1990. Moreover, the annual number of maternal deaths decreased by $43.0 \%$ from approximately 532,000 in 1990 to an estimated 303,000 in 2015. The approximate global lifetime risk of a maternal death fell considerably from 1 in 73 to 1 in $180 .{ }^{5}$

In Nepal, maternal mortality has decreased by $71.4 \%$ from901/100,000 population in 1990 to 258/100,000 population in $2015 .^{6}$ Of the estimated 927,000 pregnancies that take place in Nepal every year, $40.0 \%$ of them are considered to be highly risky for both the mother andthe child. ${ }^{7}$ The Iron SupplementationProgram for pregnant women to prevent anemia, maternal and neonatal tetanus elimination program, tetanus and diphtheria toxoid(Td)vaccination of pregnant women and clean delivery practice were key strategies to achieve low maternal mortality and morbidity. ${ }^{7}$ Demographic and sociocultural factors including maternal age, number of living children, education, place of residence, occupation, religion and ethnicity influence the use of maternal health care services. ${ }^{8}$

The major complications that account in $80.0 \%$ of all maternal deaths are severe bleeding, infections after childbirth, high blood pressure during pregnancy and unsafe abortion. ${ }^{9}$ Antenatal care, delivery by skilled health professionals, and postnatal care would ensure timely management and treatment of complications to reduce maternal deaths. Hence, the objective of the study was to evaluate the utilization of ANC services by the women of age groups of 15-44 years at urban areas of Pokhara Municipality.

\section{MATERIAL AND METHOD}

It was a descriptive cross-sectional study conducted in Pokhara sub-metropolitan among three randomly selected wards (now merged in municipality) namely, Bhalam, Phulbari and Kanhu. The study was 
conducted for one years' duration starting from January to December 2015. The study populations were pregnant women of reproductive age group between 15-44 years of age and married non-pregnant women of reproductive age having at least one child below two years of age.

Women of reproductive age groups of between 15-44 years of age were aimed having specific inclusion criteria of bearing at least one youngest child below the age of two years to reduce recall bias. Pregnant women if present were also included. Sample size was 240 including 80 participants from each selected ward with a total of 240 participants.

Structured and semi-structured questionnaire were used after translating it into Nepali language and pretesting. Data collection was done by the researcher herself getting help of the local female community health volunteers (FCHVs) to identify the household having women with children below two years of age. Face to face interview methods were used as a data collection technique with the constant involvement of principle investigator during data collectionto ensure quality. Data entered into Microsoft excel were translated into SPSS (Statistical package for social sciences) version 21 and analysis were done. Both descriptive (percentage and mean) and inferential (chi square test) statistics were computed.
Ethical approval was taken from the Institutional Review Committee (IRC) of Manipal College of Medical Sciences preceding the study. Written and verbal consents were taken from all the potential participants. National guidelines of Nepal indicates that it is not necessary to obtain a consent from parents or guardians in the case of adolescent. So the consent was taken from the adolescent mothers themselves.

\section{RESULTS}

This study was carried out among three randomly selected wards of Pokhara SubMetropolitan city namely Bhalam, Phulbari and Kanhu. A total of 240 women of reproductive age group were included in the study.

\section{Table 1: Occurrence of ANC visits}

\begin{tabular}{llll}
$\begin{array}{c}\text { Indicat } \\
\text { ors }\end{array}$ & f & \% \\
\hline $\begin{array}{l}\text { ANC } \\
\text { visits }\end{array}$ & Yes & 233 & 97.1 \\
Total & & 7 & 2.9 \\
\hline $\begin{array}{l}\text { Numbe } \\
\text { r of }\end{array}$ & 1-3 visits & $\mathbf{2 4 0}$ & $\mathbf{1 0 0 \%}$ \\
ANC & Not visits & 134 & $41.2 \%$ \\
visits & & 7 & $2.9 \%$ \\
Total & 1st Trimester & 187 & $80.3 \%$ \\
\hline $\begin{array}{l}\text { Charact } \\
\text { eristics }\end{array}$ & 2nd Trimester & 40 & $17.2 \%$ \\
& 3rd Trimester & 6 & $2.6 \%$ \\
\hline Total & & 233 & $100 \%$ \\
\hline
\end{tabular}

* $\mathrm{C}=$ Characteristics, $\mathbf{f}=$ Frequency,

Around $97.0 \%$ of women had visited ANC during their recent pregnancy whereas only 2.9\% did not have any ANC visits. About 
$56.0 \%$ of women had $\geq 4$ ANC visits, whereas $41.0 \%$ had visited maximum up to three times. Majority (80.3\%) of the women used to seek ANC checkup during their first trimester followed by $17.2 \%$ and $2.6 \%$ in the $2^{\text {nd }}$ and $3^{\text {rd }}$ trimester respectively (Table 1).

Table 2: Association of respondent's socio-demographic characteristics with ANC visit

\begin{tabular}{|c|c|c|c|c|}
\hline \multirow[t]{3}{*}{ Indicator } & \multicolumn{2}{|l|}{ ANC visits } & \multirow[t]{3}{*}{ Total (\%) } & \multirow[t]{3}{*}{ p value } \\
\hline & Yes & No & & \\
\hline & Frequency (\%) & Frequency (\%) & & \\
\hline \multicolumn{5}{|l|}{ Age group } \\
\hline $15-19$ & $116(98.3)$ & $2(1.6)$ & $118(49.2)$ & \multirow{6}{*}{$0.0001^{*}$} \\
\hline $20-24$ & $91(100)$ & 0 & $91(37.9)$ & \\
\hline $25-29$ & 15(93.7) & $1(6.25)$ & $16(6.7)$ & \\
\hline $30-34$ & $7(70)$ & $3(30)$ & $10(4.2)$ & \\
\hline \multirow[t]{2}{*}{$35-40$} & $4(80)$ & $1(20)$ & $5(2.1)$ & \\
\hline & 233(97.1) & $7(2.9)$ & $240(100)$ & \\
\hline \multicolumn{5}{|l|}{ Ethnic class } \\
\hline Higher castes & $153(98.7)$ & $2(1.29)$ & $155(64.6)$ & \multirow{3}{*}{0.138} \\
\hline Ethnic groups & $5(83.3)$ & $1(16.6)$ & $22(9.2)$ & \\
\hline \multirow[t]{2}{*}{ Minority ethnic groups } & $59(93.6)$ & $4(6.3)$ & $63(26.2)$ & \\
\hline & 233(97.1) & $7(2.9)$ & $240(100)$ & \\
\hline \multicolumn{5}{|l|}{ Education } \\
\hline Illiterate & $32(86.4)$ & $5(13.5)$ & $37(15.4)$ & \multirow[b]{2}{*}{$0.035^{*}$} \\
\hline \multirow[t]{2}{*}{ Literate } & 201(99) & $2(1)$ & 203(84.58) & \\
\hline & 233(97.1) & $7(2.9)$ & $240(100)$ & \\
\hline \multicolumn{5}{|l|}{ Employment } \\
\hline House wife & $148(96.7)$ & $5(3.2)$ & 153(63.8) & \multirow[t]{2}{*}{0.427} \\
\hline \multirow[t]{2}{*}{ Working } & 85(97.7) & $2(2.3)$ & $87(36.2)$ & \\
\hline & 233(97.1) & $7(2.9)$ & $240(100)$ & \\
\hline \multicolumn{5}{|l|}{ Parity } \\
\hline One & $128(97.7)$ & $3(2.2)$ & $131(54.58)$ & \multirow{4}{*}{$0.0001^{*}$} \\
\hline Two & 87(97.7) & $2(2.2)$ & $89(37.08)$ & \\
\hline Three & $8(80)$ & $2(20)$ & $10(4.16)$ & \\
\hline \multirow[t]{2}{*}{ Four } & $3(75)$ & $1(25)$ & $4(1.66)$ & \\
\hline & 233(97.1) & $7(2.9)$ & $240(100)$ & \\
\hline
\end{tabular}

* indicates significance $p<0.05$

Nearly half $(49.0 \%)$ of the respondents belonged to younger age group 15-19 years followed by $38.0 \%$ respondents at $20-24$ years of age, $6.7 \%$ at $25-29$ years, $4.2 \%$ at $30-34$ 
years and $2 \%$ at $35-40$ years of age group. Higher castes like Brahmin/ Chhetri attended higher proportion (99.0\%) of ANC visits followed by lower castes minority ethnic groups (94.0\%) and Ethnic groups (83.0\%). It was found mothers who were literate had more ANC visit (99.0\%) than those who were illiterate (86.0\%). It shows that women who were housewife as well as working both had almost equal ANC visits. It shows that higher frequency (98.0\%) of ANC visits were seen among the respondents having less no of children (1-2 children) followed by (80.0\%) and $(75.0 \%)$ among the respondents having three and four children respectively. Age, education of the women and parity had significant association with ANC visits at $\mathrm{p}<$ 0.05 level (Table 2).

Table 3: Association between spouses' socio-demographic characteristics and ANC visit

\begin{tabular}{|c|c|c|c|c|}
\hline Indicators & ANC visit & & Total (\%) & p value \\
\hline & Yes & No & & \multirow{6}{*}{$0.0001 *$} \\
\hline & Frequency (\%) & Frequency (\%) & & \\
\hline Qualification & & & & \\
\hline Lower secondary & $3(50)$ & $3(50)$ & $6(3.2)$ & \\
\hline Higher secondary & 210(98.59) & $3(1.4)$ & $213(87.6)$ & \\
\hline \multirow[t]{2}{*}{ Higher education } & $20(95.2)$ & $1(4.7)$ & $21(9.7)$ & \\
\hline & 233(97.1) & $7(2.9)$ & $240(100)$ & \\
\hline \multicolumn{5}{|l|}{ Employment } \\
\hline Employed & 224(98.6) & $3(1.3)$ & $227(94.6)$ & \multirow{3}{*}{0.085} \\
\hline \multirow[t]{2}{*}{ Unemployed } & $9(69.2)$ & $4(30.7)$ & $13(5.4)$ & \\
\hline & 233(97.1) & $7(2.9)$ & $240(100)$ & \\
\hline
\end{tabular}

* indicates significance at $p<0.05$

Almost all the husbands with educational level up to higher secondary encouraged their spouses for ANC visits (99.0\%) whereas 95.0\% ANC visit was seen among the respondents having husbands with higher educational level and only $50.0 \%$ of the husbands with lower secondary level education encouraged their spouse for ANC visits which was significantly associated with ANC visits of women at $<0.05$ level. Comparing employment status with ANC visits, it shows $99.0 \%$ of the respondents with employed husbands attended ANC visits in comparison to $69.0 \%$ ANC visits by the respondents with unemployed husbands (Table 3). 
Table 4: Association between family socio-demographic characteristics and ANC visits

\begin{tabular}{|c|c|c|c|c|}
\hline \multirow[t]{3}{*}{ Indicators } & \multicolumn{2}{|c|}{ ANC visit } & \multirow[t]{3}{*}{ Total (\%) } & \multirow[t]{3}{*}{ p value } \\
\hline & Yes & No & & \\
\hline & Frequency (\%) & Frequency (\%) & & \\
\hline \multicolumn{4}{|l|}{ Family type } & \multirow{4}{*}{$0.0001^{*}$} \\
\hline Joint & 61(95.3) & $3(4.6)$ & $64(26.7)$ & \\
\hline Nuclear & 113(99.1) & $1(0.8)$ & $114(47.5)$ & \\
\hline \multirow[t]{2}{*}{ Extended } & $59(95.1)$ & $3(4.8)$ & $62(25.8)$ & \\
\hline & 233(97.1) & $7(2.9)$ & $240(100)$ & \\
\hline \multicolumn{5}{|c|}{ Family- income } \\
\hline Poor & $34(94.4)$ & $2(5.5)$ & $36(15)$ & \multirow{4}{*}{0.082} \\
\hline Low & $81(98.7)$ & $3(1.2)$ & $84(35)$ & \\
\hline Middle & $51(98)$ & $1(1.9)$ & $52(21.7)$ & \\
\hline \multirow[t]{2}{*}{ High } & $67(98.5)$ & $1(1.47)$ & $68(28.3)$ & \\
\hline & 233(97.1) & $7(2.9)$ & $240(100)$ & \\
\hline \multicolumn{5}{|l|}{ Family size } \\
\hline $2-4$ & 114(99.0) & $1(0.86)$ & $115(47.9)$ & \multirow{3}{*}{$0.047 *$} \\
\hline $5-6$ & $74(94.8)$ & $4(5.1)$ & $78(32.5)$ & \\
\hline \multirow[t]{2}{*}{$>6$} & $45(95.7)$ & $2(4.2)$ & $47(19.6)$ & \\
\hline & 233(97.1) & $7(2.9)$ & $240(100)$ & \\
\hline
\end{tabular}

* indicates level of significance $p<0.05$

Looking at the family type, it shows that the nuclear family had 99.0\% ANC visits whereas joint and extended family had 95.0\% ANC visits. Similarly, respondents with small family size (2-4) had 99.0\% ANC visits and respondents with family size of 5-6 and >6 members had 95.0\% and 96.0\% ANC visits respectively. Regarding the family income and ANC visits, it was seen that ANC visits was less among the poor respondents (95.0\%) compared to respondents from low (99.0\%), medium (98.0\%) and high (98.0\%) family income. Significant association was found with ANC visits for family type and family size of the respondents at $\mathrm{P}<0.05$ level (Table 4).

Table 5: Association between encouragement by respondents' spouses and mother- in-laws and ANC checkup

\begin{tabular}{|c|c|c|c|c|}
\hline Encouragement & \multicolumn{2}{|c|}{ ANC visit } & Total & p Value \\
\hline Husbands' encouragement & (Yes) & (No) & & \\
\hline Encourages & $\begin{array}{c}212 \\
(99.53 \%)\end{array}$ & $\begin{array}{c}1 \\
(0.4 \%)\end{array}$ & $213(83.7 \%)$ & \\
\hline Don't encourages & $21(78 \%)$ & $\begin{array}{c}6 \\
(22 \%)\end{array}$ & $27(11.2 \%)$ & $\mathrm{p}=0.0001^{*}$ \\
\hline Total & $233(97.1)$ & 7 (2.9) & $240(100)$ & \\
\hline Mother-in-law’s encouragemen & & & & \\
\hline Yes & $198(100 \%)$ & $0(0 \%)$ & $198(82.5 \%)$ & \\
\hline Most often & $21(84 \%)$ & $4(14 \%)$ & $25(10.4 \%)$ & \\
\hline Less often/Does not encourage & $14(82.3 \%)$ & $3(17.64 \%)$ & $17(6.20 \%)$ & $\mathrm{p}=0.0001^{*}$ \\
\hline Total & $233(97.1 \%)$ & $7(2.9 \%)$ & $240(100 \%)$ & \\
\hline
\end{tabular}


*Indicates significance at $p<0.05$ level

ANC visits were related with husbands' encouragement to send their spouse to have pregnancy checkup. It was statistically significant at 0.05 level which revealed that husband who encouraged their spouse to have ANC checkups ended up having as high as (99.0\%) ANC visits.Similarly, mother-in-laws' encouragement for ANC visit was also found to be statistically significant at $\mathrm{p}<0.05$ level (Table 5).

\section{DISCUSSION}

Antenatal care helps to manage healthy pregnancy which in turn results in safe delivery and a healthy newborn. But mothers rarely perceive childbearing as problematic and therefore may not seek care during pregnancy which might have adverse effects both to pregnant women and growing fetus in the womb.

This study focused to assess and relate some important socio-demographic and economic factor like age, education, parity, occupation, income, family- type, its composition, distance to ANC centre and few other factors relating to ANC utilization. Although government is committed to provide ANC services accessible and available to every pregnant women for atleast four ANC visits ${ }^{10}$ still there remains non-uniform coverage around the country. Most of the researches on ANC services utilization have been focused on rural parts, inaccessible, hard to reach population in assumption with preoccupied mindset that these areas are still deprived of transportation, education, health-care facilities and very minimal attention given by government. Just opposite to this statement, we have to think from another perspective that city area though having better facilities, may not always necessarily have better health services available and utilization as per expected. Pokhara being one of the major cities of Nepal and also one among submetropolitan city, almost it is thought that municipality or city area has little problem related to health service delivery and utilization. However, our findings in many aspects was not so much unusual or significantly different in compare to other similar types of studies done in other parts of the world and Nepal, ${ }^{11,12,13,14,15}$ except for few components which is discussed below in the preceding paragraphs. Our study revealed that ANC utilization was almost universal. i.e. $97.1 \%$ which resembles the findings from the Department of Health Services (DOHS)that reports average of (88.0\% to $98.0 \%$ ) and further same source reflected at Kaski district that it was found to be above $90.0 \%{ }^{16}$ 
Our study results have also indicated that majority of respondents utilized ANC services but personally we do not consider it to be very positive achievement and neither do it reflects it has benefitted mothers. One of the most disappointing but need to be highly focused indicatorrelated to ANC utilization that we found in our study was coverage of four ANC visits. The national data reported it to be as high as $80.0 \%$ in Pokhara but our study revealed that only $56.0 \%$ women on an average completed 4 ANC visits which was quite lower than what was reported in DOHS. ${ }^{17}$ It is very surprising to know the inadequate utilization of four ANC visit in our study area even being very near to regional and teaching hospitals and other well established private hospitals and having access to transportation as well. Inadequate ANC visits can be seen as an important indication to proceed for further in depth study to explore the exact fact behind this low coverage. In our understanding one of the reasons of low coverage might be due to underreporting of the actual cases due to recall bias. Second reason may be the respondents since the study population was based on specific criteria, it has not given sufficient space for variability in results whereas reason for having high 4 ANC visits in the national data may be due to over reporting. Nevertheless, it cannot be simply ignored and thus it opens a new area of further investigation or research in near future.

Similar to other studies, our study showed higher ANC visits among higher ethnic groups like higher castesrather than the Minority ethnic groups/Ethnic category. The studies conducted in two rural VDCs of Kathmandu districts also had similar results. ${ }^{28-30}$ This study revealed that ANC visits of literate mothers were significantly higher than the illiterates. Other studies had shown that women with secondary education are more likely to receive at least four antenatal visits than women with less or without education. ${ }^{17-22}$

The mothers representing nuclear family had higher ANC visits than the mothers from joint family which was found to be consistent with previous studies. ${ }^{23}$ Order of birth shows an inverse relationship on antenatal check up. Lower parity woman tend to give careful attention in seeking antenatal care due to their inexperience in pregnancy. Also, lower utilization of maternal health care services among higher parity women could be due to time and resource constraints faced by those with larger families. Our study revealed that women from younger age groups had more ANC visits than older women (>30 years). This result is consistent with the other similar studies which stated higher ANC visits was 
seen in younger age groups. ${ }^{17}$ In our case, it may be due to the fact that younger women are more energetic and less experienced so they seek more facilities and also they tend to have less family size which would have benefitted them having enough time to visit ANC facilities.

The most prominent and important findings of this study was motivation factors by the family members. It was one of the important factors to encourage women to go outside the home and seek the health services available to them. Similarly awareness and education of the respondents and their husband is also prerequisite to backup encouragement and convince their spouse and parents. In this case, we have found husbands' positive knowledge and encouragement by mother in laws enabled the pregnant women to utilize the services. Similar to our study, other studies revealed that husbands' involvement and encouragement is required to improve the maternal well-being and to promote ANC visits. ${ }^{24,25}$

Another important aspect was that service providers had been giving satisfactory services to their ANC clients as revealed in this study i.e. iron-folate tablets, folic acid, calcium, Td injection and counseling services. Although it was seen that counseling during ANC visits regarding birth spacing, family planning, danger signs of pregnancy and breast feeding was satisfactory but in depth study could be done further to measure their level of knowledge and practices. Similar result was seen in a study done at another city which stated the importance of proper counseling on outcome of pregnancy and child feeding. ${ }^{26}$ Also, proper counseling during ANC motivates women to complete recommended number of ANC visits and service utilization to the fullest.

Our result indicated that being very near to the health facilities and being fully aware about ANC services might guide pregnant women for ANC visits but it cannot ensure that the women will end up completing recommended 4 ANC visits. Inadequate counseling during ANC visits, attitude of ANC service providers might had rendered the women less motivated to complete 4 ANC visits. Similar results were seen in studies done at various places which stated that inadequate counseling and bad attitudes of service providers during ANC visit might end up to lesser number of ANC visits, low awareness of danger signs and finally home delivery by the pregnant mothers. ${ }^{27-29}$

Our study noted that the physical proximity to the ANC centre had resulted in satisfactory ANC visits. Similar studies 
stated that near distance to the ANC centre from the residence plays important role in utilization of ANC. ${ }^{15}$ However, in our study physical proximity to the ANC centre failed to increase the desired number of 4 ANC visits despite having higher rate of ANC utilization.

This study revealed that the income of the respondents' family had no significant influence on ANC visits. In contrast, similar other studies had indicated that higher economic condition of the family can lead the pregnant women to utilize ANC services more than the women from poor families. ${ }^{30}$ This may be due to the fact that our study area was near to ANC centre as well as high awareness and satisfactory educational status of the respondents and their spouse might had resulted on more ANC visits despite the fact that majority of the respondents in our study were from low and middle income families.

Our study indicated that $98.0 \%$ of the respondents sought skilled manpower (doctor, nurse, midwives) for ANC checkups that comes to be higher than the national average which stated that only $58 \%$ women sought skilled manpower during ANC visits. ${ }^{16}$ It can be concluded from our study that easy availability and accessibility of skilled health care providers (fact that our study area was near to tertiary hospitals, regional hospitals and many private nursing homes) would result in seeking more consultation from them.

Due to the resource constraints, the researcher was not able to cover large population and areas as a result the findings cannot be generalized for whole Nepal.There is a possibility of recall bias in the study, some of the respondents were unable to recall well the various information concerning antenatal clinic-visits.

\section{CONCLUSION}

Although nearly all of the women received ANC services, there was variation in the ANC service taking as per the age, educational attainment of the women and husband and parity of the woman. The study has given sufficient evidence and identified family encouragement as an important motivating factor for ANC service utilization.

Local authority and concerned must design program targeting head of household, husband and mother-in-law in creating more awareness regarding importance ofANC services. Conduction of detailed studies in futureto explore quality of services is recommended. 


\section{REFERENCES}

1. Park K. Antenatal care. Park's text book of preventive and social medicine. $22^{\text {nd }}$ ed. India, Premnagar, Jabalpur, 2013;483-487.

2. Jafarey SN. Maternal and perinatal health in Pakistan. The proceedings of a workshop. Karachi: TWEL publishers, 1993 Jan; pp.26-27.

3. McDonagh M. Is antenatal care effective in reducing matemal morbidity and mortality? Health Pol Plann. 1996; 11:1-15.

[PubMed]

4. Kwast BE. Reduction of maternal and perinatal mortality in rural and peri-urban setting: what works? Eur J Obstet Gynecol Reprod Biol. 1996; 69(1):47-53.

Full Text

5. World Health Organization (WHO). Trends in maternal mortality: 1990 to 2015 Tech. Rep., WHO, UNICEF, UNFPA and The World Bank Estimates. [Online]2015[cited 2016 Sept 16].

Full Text

6. Maternal Mortality Estimation Inter-Agency Group.Maternal mortality in 1990-2015.WHO, UNICEF, UNFPA, World Bank Group, and United Nations Population Division.[Online] 2015 [cited 2016 Dec 18]. [Link]

7. United Nations Children Fund (UNICEF). Children and Women of Nepal: A Situation Analysis.Kathmandu:UNICEF Nepal;1996.

8. Nylander PP, Adkunle AO. Antenatal care in developing countries .1990; 4(1): 169-186.

$\underline{\text { Full Text }}$

9. Carroli G, Rooney C, Villar J. How effective is antenatal care in preventing maternal mortality and serious morbidity? An overview of the evidence.Pediatricsand Perinatal Epidemiology. 2001;1(5): 1-42. Available from:

[Link]

10. World Health Organization. Mother-Baby Package: Implementing safe motherhood in countries, practical guide. Geneva,[Online] 1996 [cited 2016 Dec 1].

[Link]

11. Lumbiganon P, Martis R, Laopaiboon M, Festin MR, Ho JJ, Hakimi M. Ante-natal breastfeeding educationfor increasing breastfeeding duration. Cochrane database of systemic reviews.[Online] 2016 [cited 2016 Dec 7].

Full Text

12. Lincetto O, Mothebesoane S, Gomez P, MunjanjaS.Antenatal care.Oppturn- itiesfor
Africa’s newborn.[Online] 2015 [cited 2016 Oct 13]. [Link]

13. Department of health services .Annual report of Department of health services. Family Health: Safemotherhood and Newborn Health. Kathmandu, 2014 /2015;80-86.

14. Acharya LB, Ueland J. Maternal and child health services in rural Nepal: does occur or quality matter more? Health Policy Plan. 2000;15(2):223-9.

Full Text

15. Sharma SK, Sawaungdee Y, Sirirassamee B. Access to Health:Women's status and utilization of maternal health services in Nepal. J Biosoc Sci.2007;39 (05):671-92.

[Link]

16. Ministry of Health and Population (MOHP). Nepal Demographic and Health Survey (NDHS).New ERA and Macro International Inc.Antenatal care. Kathmandu, March 2012; pp 119-144.

17. Onasoga OA, Afolayan JA, Oladimeij BD. Factor's influencing utilization of antenatal care services among pregnant women in Ife Central LGA, Osun State Nigeria. Advances in Applied Science Research. 2012; 3 (3):1309-1315. Full Text

18. Becker S, Peters DH, Gray RH, Ggultiano C, Blake RE. The determinant of use of maternal child health services in Metro Cebu, the Philippines. Health TransitionRev. 1993;3:77-89. Full Text

19. Matsumura M, Gubhaju B. Women's Status, Household Structure and the Utilization of Maternal Health Services in Nepal: Even primaryleve1 education can significantly increase the chances of a woman using maternal health care from a modem health facility. Asia-Pacific Population Journal. 2001; 16(1): 23-44.

Full Text

20. Woldemicael G, Tenkorang EY. Women's Autonomy and Maternal Health Seeking Behavior in Ethiopia. Maternal and Child Health Journal. 2010; 14(6):988-98. Available from: Full Text

21. Mekonnen Y, Mekonnen A. Factors influencing the use of maternal healthcare services in Ethiopia. Journal of Health Population and Nutrition. 2003; 21(4):374-82. Full Text

22. Bhatia JC, Cleland J. Determinants of maternal care in a region of South India. Health Transition Review. 1995; 5: 127-142.

Full Text

23. Pokhrel, BR, Sharma P, Bhatta B, Bhandari B, Jha N. Health seeking behavior during pregnancy and child birth among Muslim women of Biratnager, Nepal. Nepal Medical College J. 2012;14(2):125-128. 
24. Tuladhar H, Dhakal N. Impact of Antenatal care on maternal and perinatal outcome: A study at Nepal Medical College Teaching Hospital. Nepal journal of Obstetrics and Gynaecology.2011;6(2):37-43.

Full Text

25. Karkee R, Hlee A, Binns CW. Why Women do not utilize maternity services in Nepal: A literature review.[cited 2015 Nov 6]. [Link]

26. Gamble C, Ekwaru PJ, Garner P, TerKuile FO. Insecticide-treated nets for the prevention of malaria in pregnancy: a systematic review of randomized controlled trials. PLoS Medicine. 2007;4:e107.

PubMed

27. Malhotra C, Malhotra R, Ostbye T, Subramanian SV. Maternal autonomy and child health care utilization in India: results from the national family health survey. Asia Pac J Public Health. 2014; 26(4):401-13.

Full Text

28. Sharma B. Utilization of antenatal care services in Nepal. Nepal Popul Journal. 2004; 11(10):79-97.

29. Simkhada B, Porter MA, Van Teijlingen ER. The role of mothers-in-law in antenatal care decisionmaking in Nepal: a qualitative study. BMC Pregnancy Childbirth. 2010; 10(1):34. Full Text

30. The Partnership for Maternal, Newborn \& Child Health. The PMNCH 2013 Report-Analysing Progress on Commitments to the Global Strategy for Women'sand Children's Health. [Online] 2013 [cited 2015 Sept 23]. 2013. Full Text 